\title{
BMJ
}

\section{Effect of tobacco smoking on survival of men and women by social position: a 28 year cohort study}

\author{
Laurence Gruer, director of public health science, ${ }^{1}$ Carole L Hart, research fellow, ${ }^{2}$ David S Gordon, head of \\ public health observatory division, ${ }^{1}$ Graham C M Watt, professor of general practice ${ }^{3}$
}

${ }^{1} \mathrm{NHS}$ Health Scotland, Elphinstone House, Glasgow G2 2AF

${ }^{2}$ Public Health and Health Policy, Division of Community-based

Sciences, University of Glasgow, Glasgow G12 8RZ

${ }^{3}$ General Practice and Primary Care, Division of Communitybased Sciences, University of Glasgow, Glasgow G12 9LX

Correspondence to: $\mathrm{L}$ Gruer

Laurence.Gruer@health.scot.nhs.uk

Cite this as: $B M J$ 2009;338:b480 doi:10.1136/bmj.b480

\section{ABSTRACT}

Objective To assess the impact of tobacco smoking on the survival of men and women in different social positions.

Design A cohort observational study.

Setting Renfrew and Paisley, two towns in west central Scotland.

Participants 8353 women and 7049 men aged 45-64 years recruited in 1972-6 (almost $80 \%$ of the population in this age group). The cohort was divided into 24 groups by sex (male, female), smoking status (current, former, or never smokers), and social class (classes I + II, II non-manual, III manual, and IV + V) or deprivation category of place of residence.

Main outcome measure Relative mortality (adjusted for age and other risk factors) in the different groups; KaplanMeier survival curves and survival rates at 28 years. Results Of those with complete data, 4387/7988 women and $4891 / 6967$ men died over the 28 years. Compared with women in social classes I + II who had never smoked (the group with lowest mortality), the adjusted relative mortality of smoking groups ranged from 1.7 (95\% confidence interval 1.3 to 2.3 ) to 4.2 (3.3 to 5.5 ). Former smokers' mortalities were closer to those of never smokers than those of smokers. By social class (highest first), age adjusted survival rates after 28 years were $65 \%, 57 \%$, $53 \%$, and $56 \%$ for female never smokers; $41 \%, 42 \%$, $33 \%$, and $35 \%$ for female current smokers; $53 \%, 47 \%$, $38 \%$, and $36 \%$ for male never smokers; and $24 \%, 24 \%$, $19 \%$, and $18 \%$ for male current smokers. Analysis by deprivation category gave similar results.

Conclusions Among both women and men, never smokers had much better survival rates than smokers in all social positions. Smoking itself was a greater source of health inequality than social position and nullified women's survival advantage over men. This suggests the scope for reducing health inequalities related to social position in this and similar populations is limited unless many smokers in lower social positions stop smoking.

\section{INTRODUCTION}

The adverse health consequences of tobacco smoking have been known for over 50 years, but the full impact of lifelong smoking has only recently emerged. ${ }^{1}$ This is because there are few studies where large numbers of smokers and non-smokers have been compared for long enough. Doll and colleagues have shown that persistent cigarette smoking from early adulthood tripled age-specific mortality among male British doctors. ${ }^{1}$ However, few studies have directly assessed the long term impact of smoking across the social spectrum and, to our knowledge, none has included women. On the other hand, a large body of work over the past 30 years has highlighted the persistent and apparently widening health inequalities between people with different socioeconomic status in many countries. $^{2}$ Although the contribution of smoking to these inequalities has been acknowledged, ${ }^{34}$ the implicit assumption is generally that greater affluence and better health always go hand in hand.

We report here the findings of a prospective study of about 15000 men and women in two urban communities in the west of Scotland where smoking has been common for many decades. Our aim was to assess the relative impact on participants' health of smoking, sex, and social position by analysing their survival rates over 28 years.

\section{METHODS}

The Renfrew and Paisley study (one of the Midspan studies) is a long term, community based, cohort study. It was started in 1972 in the neighbouring towns of Renfrew and Paisley in west central Scotland when all residents then aged between 45 and 64 years were invited to participate. ${ }^{5}$ In all, 8353 women and 7049 men were recruited during 1972-6, achieving a participation rate of nearly $80 \%$. Participants completed a detailed questionnaire (including questions on usual occupation, address, and smoking habit), which was checked when they attended a screening examination. Retired participants reported their last full time occupation, and women who were housewives reported their husband's occupation.

Social class was obtained from the occupation according to the contemporaneous Classification of Occupations. ${ }^{6}$ Based on its postcode, each participant's place of residence was assigned to one of seven "deprivation categories" using an area based socioeconomic measure calculated by the method of Carstairs and Morris. ${ }^{7}$ Participants were classified as never smokers, current smokers, or former smokers. 
Former smokers were defined as having stopped smoking for at least a year before screening. Those who had stopped for less than a year were defined as current smokers.

The screening examination included recording of blood pressure; forced expiratory volume in 1 second $\left(\mathrm{FEV}_{1}\right)$, measured with a Garthur Vitalograph; height and weight, allowing body mass index to be calculated; and plasma cholesterol concentration from a nonfasting blood sample..$^{5}$ The recorded $\mathrm{FEV}_{1}$ was presented as a percentage of expected $\mathrm{FEV}_{1}$, which was derived from regression equations based on a healthy subset of the cohort. ${ }^{8}$

We obtained details of participants' dates and causes of death occurring in the 28 years after screening from the General Register Office for Scotland. The 24 participants who were lost to follow-up were excluded from the study, and 115 participants who were known to have left the UK were censored at their date of departure.

Data on social class were missing for 351 women and 72 men, leaving 7988 women and 6967 men of known social class. Because of small numbers in some classes, we used only four categories of social class - classes I plus II (highest), III non-manual, III manual, and IV plus V (lowest). Eleven women and 23 men had missing data on deprivation category of place of residence, leaving 8328 women and 7016 men with a known deprivation category of place of residence. Because of small numbers of participants in some categories (and none at all in category 2), we converted the seven deprivation categories to four-1 plus 3 (most affluent), 4, 5, and 6 plus 7 (least affluent).

\section{Statistical analyses}

We categorised the participants into 24 mutually exclusive groups according to their sex, smoking status (current, former, or never smoker) when they completed the questionnaire in 1972-6, and social class or deprivation category. We performed separate analyses by social class and deprivation category.

We used Cox's proportional hazards regression models, adjusted for age and other risk factors, to obtain estimates of relative all cause mortality (with $95 \%$ confidence intervals) by means of Stata, release 9 .

Table 1|Smoking status at recruitment of 7988 women and 6967 men aged 45-64 years categorised by social class. Values are numbers (percentages)

\begin{tabular}{lcccc} 
& \multicolumn{4}{c}{ Social class } \\
\cline { 2 - 5 } Smoking status & $\mathrm{I}+\mathrm{II}$ & $\mathrm{IIIN}$ & $\mathrm{IIIM}$ & $\mathrm{IV}+\mathrm{V}$ \\
Women: & $\mathrm{n}=1451$ & $\mathrm{n}=1975$ & $\mathrm{n}=1486$ & $\mathrm{n}=3076$ \\
\hline Never smokers & $693(47.8)$ & $933(47.2)$ & $737(49.6)$ & $1289(41.9)$ \\
\hline Current smokers & $623(42.9)$ & $874(44.3)$ & $653(43.9)$ & $1585(51.5)$ \\
\hline Former smokers & $135(9.3)$ & $168(8.5)$ & $96(6.5)$ & $202(6.6)$ \\
\hline Men: & $\mathrm{n}=1329$ & $\mathrm{n}=829$ & $\mathrm{n}=2813$ & $\mathrm{n}=1996$ \\
\hline Never smokers & $306(23.0)$ & $149(18.0)$ & $418(14.9)$ & $292(14.6)$ \\
\hline Current smokers & $620(46.7)$ & $448(54.0)$ & $1734(61.6)$ & $1276(63.9)$ \\
\hline Former smokers & $403(30.3)$ & $232(28.0)$ & $661(23.5)$ & $428(21.4)$ \\
\hline
\end{tabular}

IIIN=III non-manual. IIIM=III manual.
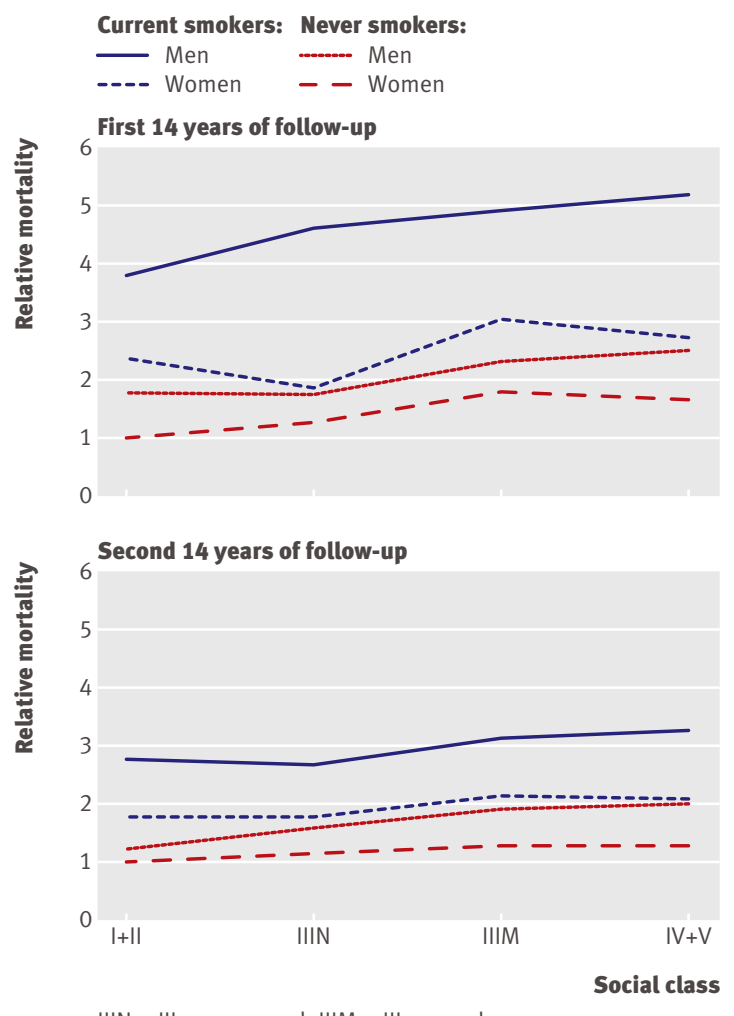

$\mathrm{IIIN}=\mathrm{III}$ non-manual, IIIM = III manual

Fig 1 Age adjusted, relative, all cause mortality in the first and second 14 years of follow-up of women and men aged 45-64 years and who never smoked or currently smoked at recruitment categorised by social class (with women in social classes I and II who never smoked as the reference group)

Missing values for systolic blood pressure, body mass index, plasma cholesterol concentration, and percentage predicted $\mathrm{FEV}_{1}$ were added using the sex specific means. The proportionality assumption was violated when using the entire 28 years of follow-up as the hazards changed over time. We redid the analyses for deaths in the first 14 years and then in second 14 years, and the proportional hazards assumptions were satisfied. In the later period, the analyses excluded participants who had died or had left the UK in the first 14 years. We produced Kaplan-Meier survival curves and survival rates over the 28 years of follow-up using Stata, release 9 .

\section{RESULTS}

Table 1 shows the smoking status among women and men in each social class at the time of recruitment. Among women the proportion of current smokers ranged from $43 \%$ in the highest social classes (I+II) to $52 \%$ in the lowest $(\mathrm{IV}+\mathrm{V})$, and among men it ranged from $47 \%$ to $64 \%$. The women reported smoking an average of 15.5 cigarettes a day, and the men reported 20.4 . Overall, $46 \%$ of the women and $17 \%$ of the men had never smoked. Female and male former smokers had stopped an average of about 12 and 14 years before recruitment respectively.

Table 2 gives the total number of deaths of women and men in each social class and the relative mortality 
Table 2| Relative all cause mortality in the first and second 14 years of follow-up of women and men aged 45-64 years at recruitment categorised by social class (with women in social classes I and II as the reference group)

\begin{tabular}{|c|c|c|c|c|}
\hline & \multicolumn{4}{|c|}{ Social class } \\
\hline & $I+I I$ & IIIN & IIIM & $I V+V$ \\
\hline \multicolumn{5}{|l|}{ First 14 years' follow-up } \\
\hline Women: & $n=1451$ & $n=1975$ & $n=1486$ & $n=3076$ \\
\hline No of deaths & 220 & 271 & 341 & 631 \\
\hline \multicolumn{5}{|l|}{ Relative mortality $(95 \% \mathrm{Cl})$ : } \\
\hline Adjusted for age only & 1 & $0.91(0.76$ to 1.08$)$ & 1.38 (1.17 to 1.64$)$ & 1.31 (1.12 to 1.52$)$ \\
\hline Fully adjusted* & 1 & $0.88(0.74$ to 1.05$)$ & 1.25 (1.05 to 1.48$)$ & 1.15 (0.98 to 1.34$)$ \\
\hline Men: & $n=1329$ & $n=829$ & $n=2813$ & $n=1996$ \\
\hline No of deaths & 305 & 245 & 886 & 695 \\
\hline \multicolumn{5}{|c|}{ Relative mortality $(95 \% \mathrm{Cl})$ : } \\
\hline Adjusted for age only & 1.65 (1.39 to 1.97$)$ & 2.02 (1.69 to 2.43$)$ & 2.38 (2.05 to 2.76$)$ & $2.50(2.15$ to 2.91$)$ \\
\hline Fully adjusted* & 1.63 (1.37 to 1.95$)$ & 1.85 (1.54 to 2.22$)$ & 2.10 (1.80 to 2.44$)$ & 2.12 (1.81 to 2.47$)$ \\
\hline \multicolumn{5}{|l|}{ Second 14 years' follow-up } \\
\hline Women: & $n=1217$ & $n=1693$ & $n=1136$ & $n=2427$ \\
\hline No of deaths & 482 & 711 & 569 & 1162 \\
\hline \multicolumn{5}{|l|}{ Relative mortality $(95 \% \mathrm{Cl})$ : } \\
\hline Adjusted for age only & 1 & 1.07 (0.96 to 1.20$)$ & 1.24 (1.10 to 1.40$)$ & 1.24 (1.12 to 1.38$)$ \\
\hline Fully adjusted* & 1 & 1.06 (0.94 to 1.19$)$ & $1.16(1.03$ to 1.31$)$ & 1.14 (1.03 to 1.27$)$ \\
\hline Men: & $n=1016$ & $n=582$ & $\mathrm{n}=1907$ & $n=1290$ \\
\hline No of deaths & 506 & 327 & 1115 & 812 \\
\hline \multicolumn{5}{|l|}{ Relative mortality $(95 \% \mathrm{Cl})$ : } \\
\hline Adjusted for age only & 1.48 (1.30 to 1.67$)$ & 1.71 (1.48 to 1.96$)$ & 1.96 (1.76 to 2.18$)$ & 2.11 (1.89 to 2.37 ) \\
\hline Fully adjusted* & 1.51 (1.33 to 1.71$)$ & $1.66(1.44$ to 1.91$)$ & 1.89 (1.69 to 2.10$)$ & 1.99 (1.77 to 2.23$)$ \\
\hline
\end{tabular}

for women and men in each social class compared with women in social classes I and II, the group with the lowest mortality. Over the 28 years of follow-up, a total of 4387 women $(55 \%)$ and 4891 men $(70 \%)$ had died. Women had significantly lower mortality than men in every social class throughout follow-up and after adjustment for age and other risk factors.

Tables 3 and 4 show the relative mortality of women and men in each social class according to their smoking status, compared with women in social classes I and II who never smoked. Smokers had higher mortality than never smokers among both women and men and in every social class during both periods of follow-up. The rates among male smokers were particularly high in the first 14 year period when they were between 3.8 and 5.1 times as high as those of women in the highest social class who never smoked, when adjusted for age only. Adjusting for other risk factors (systolic blood pressure, body mass index, plasma cholesterol, and percentage predicted $\mathrm{FEV}_{1}$ ) attenuated the rates slightly to between 3.5 and 4.2 times as high. In the second 14 years of follow-up rates were between 2.7 and 3.3 times as high when adjusted for age and between 2.6 and 3.1 as high when also adjusted for the other risk factors. Never smokers in social classes IV and V had lower mortality than current smokers in social classes I and II among both men and women in both follow-up periods. Figure 1 clearly shows the consistently large differences between the mortality of never smokers and smokers across the social classes throughout follow-up.
The analysis by deprivation category gave a similar pattern of results to those by social class (see extra material on bmj.com).

Tables 3 and 4 show that mortality among former smokers was lower than that among current smokers, particularly in the second follow-up period when the rates of never smokers and former smokers were very similar. Figure 2 shows this clearly for men. The results for women were similar.

Tables 3 and 4 also show that most deaths from lung cancer occurred in current smokers. There were 842 lung cancer deaths, $5 \%$ of which occurred among never smokers, 9\% among former smokers, and 86\% among current smokers. Lung cancer caused $1.8 \%$ of deaths in never smokers, $5.3 \%$ in former smokers, and $13.4 \%$ in current smokers.

Table 5 shows the proportion of never smokers and current smokers in different social classes who were still alive at the end of the 28 years of follow-up, ranging from $65 \%$ of female never smokers in social classes I and II to $18 \%$ of male smokers in social classes IV and V. Women were more likely to have survived than men of the same social class and smoking status. Among both women and men, survival of never smokers in even the lowest social classes was greater than current smokers in all social classes. Table 5 also shows that female smokers were less likely to have survived than male never smokers in all social classes.

Figure 3 shows the age adjusted survival curves for women and men in the highest and lowest social classes. 
The downward trajectories of the survival curves were distinctly steeper for current smokers than for never smokers. For both men and women, survival of never smokers in the lowest social classes was much better than that of smokers of the same sex in the highest social classes. Similar survival curves were produced when we analysed the data by deprivation category rather than social class (see extra material on bmj.com).

\section{DISCUSSION}

To our knowledge this is the first cohort study to have examined the long term impact of tobacco smoking on survival in a large sample of older women and men in relation to their social position. Our report follows previous analyses of this cohort which showed the interacting influences of smoking, sex, and social position on cardiovascular risk factors and mortality ${ }^{910}$ and predicted survival to age $75 .{ }^{11}$ The present study's key finding is that smokers in all social positions have poorer survival than those who never smoked in even the lowest social positions. Furthermore, the differences in survival between smokers and never smokers were greater than those between smokers in different social positions. This suggests that the scope for reducing health inequalities related to social position in this and similar populations is limited unless many smokers in lower social positions can be enabled to stop smoking.

Table 3 | Relative all cause mortality in the first 14 years of follow-up of women and men aged 45-64 years at recruitment categorised by social class and smoking status (with women in social classes I and II who never smoked as the reference group)

\begin{tabular}{|c|c|c|c|c|}
\hline \multirow[b]{2}{*}{ Smoking status } & \multicolumn{4}{|c|}{ Social class } \\
\hline & $1+I I$ & IIIN & IIIM & $\mathrm{IV}+\mathrm{V}$ \\
\hline \multicolumn{5}{|l|}{ Women } \\
\hline Never smokers: & $n=693$ & $n=933$ & $\mathrm{n}=737$ & $\mathrm{n}=1289$ \\
\hline $\begin{array}{l}\text { No of deaths (deaths from } \\
\text { lung cancer) }\end{array}$ & $68(1)$ & $118(2)$ & $147(5)$ & $227(4)$ \\
\hline \multicolumn{5}{|l|}{ Relative mortality $(95 \% \mathrm{Cl})$ : } \\
\hline Adjusted for age only & 1 & $1.28(0.95$ to 1.72$)$ & 1.79 (1.34 to 2.38$)$ & 1.65 (1.26 to 2.16$)$ \\
\hline Fully adjusted* & 1 & $1.24(0.92$ to 1.67$)$ & 1.63 (1.22 to 2.17$)$ & 1.44 (1.10 to 1.89$)$ \\
\hline Current smokers: & $n=623$ & $n=874$ & $n=653$ & $n=1585$ \\
\hline $\begin{array}{l}\text { No of deaths (deaths from } \\
\text { lung cancer) }\end{array}$ & $123(9)$ & $133(18)$ & $172(15)$ & $359(37)$ \\
\hline \multicolumn{5}{|l|}{ Relative mortality $(95 \% \mathrm{Cl})$ : } \\
\hline Adjusted for age only & 2.37 (1.76 to 3.18$)$ & 1.86 (1.39 to 2.49$)$ & $3.02(2.28$ to 4.0$)$ & 2.73 (2.11 to 3.54$)$ \\
\hline Fully adjusted* & 2.24 (1.67 to 3.02$)$ & 1.70 (1.27 to 2.27$)$ & 2.54 (1.91 to 3.36$)$ & 2.28 (1.76 to 2.96$)$ \\
\hline Former smokers: & $n=135$ & $n=168$ & $n=96$ & $n=202$ \\
\hline $\begin{array}{l}\text { No of deaths (deaths from } \\
\text { lung cancer) }\end{array}$ & $29(0)$ & $20(2)$ & $22(0)$ & $45(2)$ \\
\hline \multicolumn{5}{|l|}{ Relative mortality $(95 \% \mathrm{Cl})$ : } \\
\hline Adjusted for age only & 2.48 (1.60 to 3.82$)$ & 1.35 (0.82 to 2.22$)$ & $2.29(1.42$ to 3.71$)$ & 2.20 (1.51 to 3.20$)$ \\
\hline Fully adjusted* & 2.39 (1.55 to 3.70$)$ & 1.37 (0.83 to 2.26$)$ & 1.95 (1.21 to 3.16$)$ & 1.79 (1.23 to 2.62 ) \\
\hline \multicolumn{5}{|l|}{ Men } \\
\hline Never smokers: & $n=306$ & $n=149$ & $\mathrm{n}=418$ & $\mathrm{n}=292$ \\
\hline $\begin{array}{l}\text { No of deaths (deaths from } \\
\text { lung cancer) }\end{array}$ & $47(2)$ & $25(0)$ & $81(5)$ & $68(0)$ \\
\hline \multicolumn{5}{|l|}{ Relative mortality $(95 \% \mathrm{Cl})$ : } \\
\hline Adjusted for age only & 1.80 (1.24 to 2.60$)$ & $1.76(1.11$ to 2.78$)$ & 2.28 (1.65 to 3.15$)$ & 2.44 (1.75 to 3.42$)$ \\
\hline Fully adjusted* & 1.84 (1.27 to 2.67$)$ & 1.70 (1.07 to 2.69$)$ & 2.18 (1.58 to 3.01$)$ & 2.14 (1.53 to 3.0$)$ \\
\hline Current smokers: & $n=620$ & $n=448$ & $\mathrm{n}=1734$ & $n=1276$ \\
\hline $\begin{array}{l}\text { No of deaths (deaths from } \\
\text { lung cancer) }\end{array}$ & $183(32)$ & $162(19)$ & $637(103)$ & $502(92)$ \\
\hline \multicolumn{5}{|l|}{ Relative mortality $(95 \% \mathrm{Cl})$ : } \\
\hline Adjusted for age only & $3.79(2.87$ to 5.0$)$ & 4.57 (3.44 to 6.07$)$ & 4.88 (3.80 to 6.27$)$ & $5.10(3.96$ to 6.57$)$ \\
\hline Fully adjusted* & $3.48(2.63$ to 4.60$)$ & $3.92(2.95$ to 5.21$)$ & $4.08(3.17$ to 5.25$)$ & $4.23(3.28$ to 5.47$)$ \\
\hline Former smokers: & $n=403$ & $n=232$ & $n=661$ & $n=428$ \\
\hline $\begin{array}{l}\text { No of deaths (deaths from } \\
\text { lung cancer) }\end{array}$ & $75(4)$ & $58(2)$ & $168(17)$ & 125 (11) \\
\hline \multicolumn{5}{|l|}{ Relative mortality $(95 \% \mathrm{Cl})$ : } \\
\hline Adjusted for age only & 2.11 (1.52 to 2.92 ) & 2.52 (1.77 to 3.58$)$ & 2.98 (2.25 to 3.95$)$ & 3.09 (2.30 to 4.15$)$ \\
\hline Fully adjusted* & 2.06 (1.49 to 2.87 ) & 2.32 (1.63 to 3.30$)$ & 2.68 (2.02 to 3.56$)$ & 2.62 (1.95 to 3.53$)$ \\
\hline
\end{tabular}

IIIN=III non-manual. IIIM=III manual.

${ }^{\star}$ Adjusted for age, systolic blood pressure, body mass index, plasma cholesterol concentration, and percentage predicted FEV 1 
Strengths and weaknesses of the study

Our analysis has several important strengths. The study population includes almost $80 \%$ of all the 45-64 year olds in two typical industrial towns in the west of Scotland, an unusually high response rate. The prevalence of smoking in the study population is high, the duration of follow-up long, and the completeness of data excellent. The inclusion of both women and men and the categorisation of almost all participants by their social class or the deprivation category of their place of residence allow the interaction of smoking, sex, and social position to be studied. This combination of features suggests the findings are robust.

The study also has several limitations. Firstly, there were relatively few people in the higher social positions in the study population. In order to achieve adequate numbers, we had to amalgamate groups across a relatively wide range of higher social positions. This limited our ability to explore the possible health gradients within this section of the population.

Secondly, occupation is a relatively weak measure of social position, particularly for non-working women who are classified according to their husband's occupation. In addition, a previous analysis of this cohort has shown that social class and place of residence make independent contributions to mortality. ${ }^{9}$ As a consequence, the true slope of the social position gradient due to factors other than smoking could be greater than our results suggest.

Thirdly, smoking status was recorded only at recruitment, and for the purposes of the analysis we have assumed that all current smokers continued to smoke. Subsequent trends in smoking prevalence in Scotland indicate that substantial numbers of participants must have stopped smoking after recruitment, and relatively more of those who stopped would have been in higher social positions. For example, in the most recent survey of smoking in Scotland in 2007, $13 \%$ and $40 \%$ respectively of the most affluent and most deprived fifths of the population smoked, ${ }^{12}$ compared with $45 \%$ and $58 \%$ respectively of the highest and

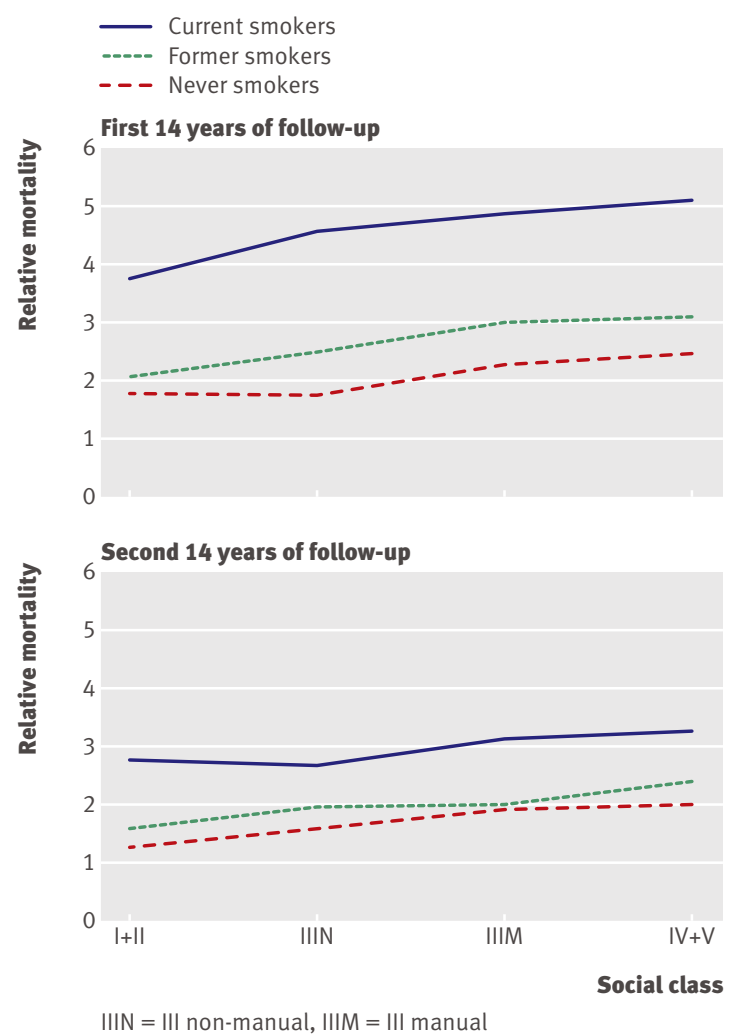

Fig 2 Age adjusted, relative, all cause mortality in the first and second 14 years of follow-up of men aged 45-64 years at recruitment categorised by social class and smoking status (with women in social classes I and II who never smoked as the reference group)

lowest social classes in our cohort at recruitment. Thus, because all participants who stopped smoking after recruitment to the present study continued to be classified as current smokers, the full impact of continued smoking across the population is very likely to be understated by our results and the differences in survival between smokers in higher and lower social positions exaggerated.
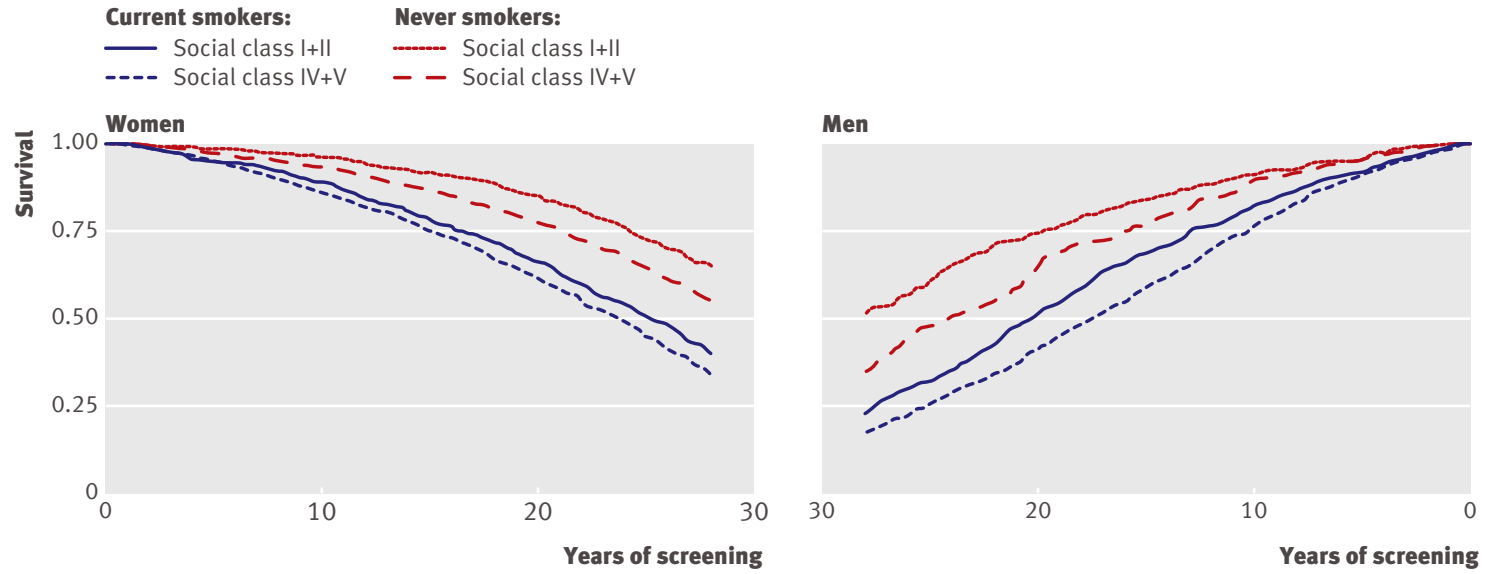

Fig 3 Age adjusted survival over 28 years of follow-up of women and men aged 45-64 years and who never smoked or currently smoked at recruitment in social classes I + II and IV + V 
Table $4 \mid$ Relative all cause mortality in the second 14 years of follow-up of women and men aged 45-64 years at recruitment categorised by social class and smoking status (with women in social classes I and II who never smoked as the reference group)

\begin{tabular}{|c|c|c|c|c|}
\hline & \multicolumn{4}{|c|}{ Social class } \\
\hline & $I+I I$ & IIIN & IIIM & $\mathrm{IV}+\mathrm{V}$ \\
\hline \multicolumn{5}{|l|}{ Women } \\
\hline Never smokers: & $n=617$ & $n=811$ & $n=584$ & $n=1056$ \\
\hline $\begin{array}{l}\text { No of deaths (deaths from } \\
\text { lung cancer) }\end{array}$ & $206(2)$ & $318(6)$ & 268 (1) & $464(9)$ \\
\hline \multicolumn{5}{|l|}{ Relative mortality $(95 \% \mathrm{Cl})$ : } \\
\hline Adjusted for age only & 1 & 1.17 (0.98 to 1.39$)$ & $1.28(1.07$ to 1.53$)$ & $1.28(1.09$ to 1.51$)$ \\
\hline Fully adjusted* & 1 & $1.16(0.97$ to 1.38$)$ & $1.19(0.99$ to 1.43$)$ & 1.18 (1.0 to 1.39$)$ \\
\hline Current smokers: & $n=495$ & $n=735$ & $n=479$ & $n=1215$ \\
\hline $\begin{array}{l}\text { No of deaths (deaths from } \\
\text { lung cancer) }\end{array}$ & $233(23)$ & $350(37)$ & $265(23)$ & $632(68)$ \\
\hline \multicolumn{5}{|l|}{ Relative mortality $(95 \% \mathrm{Cl})$ : } \\
\hline Adjusted for age only & 1.77 (1.46 to 2.13$)$ & $1.80(1.52$ to 2.14$)$ & 2.16 (1.80 to 2.59$)$ & $2.06(1.76$ to 2.41$)$ \\
\hline Fully adjusted* & 1.80 (1.49 to 2.17$)$ & 1.79 (1.51 to 2.13$)$ & 2.02 (1.68 to 2.43$)$ & 1.90 (1.63 to 2.23$)$ \\
\hline Former smokers: & $n=105$ & $n=147$ & $n=73$ & $n=156$ \\
\hline $\begin{array}{l}\text { No of deaths (deaths from } \\
\text { lung cancer) }\end{array}$ & $43(2)$ & $43(1)$ & $36(0)$ & $66(3)$ \\
\hline \multicolumn{5}{|l|}{ Relative mortality $(95 \% \mathrm{Cl})$ : } \\
\hline Adjusted for age only & $1.28(0.92$ to 1.78$)$ & 0.97 (0.70 to 1.35$)$ & 1.56 (1.09 to 2.22$)$ & $1.22(0.93$ to 1.61$)$ \\
\hline Fully adjusted* & $1.28(0.92$ to 1.77$)$ & $1.0(0.72$ to 1.39$)$ & $1.46(1.02$ to 2.08$)$ & 1.13 (0.85 to 1.49$)$ \\
\hline \multicolumn{5}{|l|}{ Men } \\
\hline Never smokers: & $n=258$ & $n=124$ & $n=333$ & $n=222$ \\
\hline $\begin{array}{l}\text { No of deaths (deaths from } \\
\text { lung cancer) }\end{array}$ & $95(3)$ & $56(1)$ & $167(3)$ & $123(1)$ \\
\hline \multicolumn{5}{|l|}{ Relative mortality $(95 \% \mathrm{Cl})$ : } \\
\hline Adjusted for age only & $1.25(0.98$ to 1.60$)$ & 1.61 (1.20 to 2.17$)$ & 1.93 (1.57 to 2.36$)$ & $2.0(1.60$ to 2.50$)$ \\
\hline Fully adjusted* & $1.33(1.04$ to 1.70$)$ & 1.67 (1.24 to 2.25$)$ & 1.93 (1.57 to 2.37$)$ & 1.90 (1.52 to 2.38$)$ \\
\hline Current smokers: & $n=435$ & $n=284$ & $\mathrm{n}=1087$ & $n=769$ \\
\hline $\begin{array}{l}\text { No of deaths (deaths from } \\
\text { lung cancer) }\end{array}$ & $262(30)$ & $177(23)$ & 701 (106) & $506(87)$ \\
\hline \multicolumn{5}{|l|}{ Relative mortality $(95 \% \mathrm{Cl})$ : } \\
\hline Adjusted for age only & $2.78(2.31$ to 3.34$)$ & 2.69 (2.20 to 3.29$)$ & 3.12 (2.67 to 3.64$)$ & 3.25 (2.76 to 3.82$)$ \\
\hline Fully adjusted* & $2.80(2.33$ to 3.36$)$ & $2.62(2.14$ to 3.21$)$ & $3.0(2.56$ to 3.51$)$ & 3.13 (2.65 to 3.69$)$ \\
\hline Former smokers: & $n=323$ & $n=174$ & $n=487$ & $n=299$ \\
\hline $\begin{array}{l}\text { No of deaths (deaths from } \\
\text { lung cancer) }\end{array}$ & $149(5)$ & $94(5)$ & 247 (14) & $183(7)$ \\
\hline \multicolumn{5}{|l|}{ Relative mortality $(95 \% \mathrm{Cl})$ : } \\
\hline Adjusted for age only & 1.61 (1.30 to 1.99$)$ & 1.99 (1.56 to 2.54$)$ & $2.0(1.66$ to 2.40$)$ & 2.37 (1.94 to 2.89$)$ \\
\hline Fully adjusted* & 1.63 (1.32 to 2.01$)$ & 1.93 (1.51 to 2.47$)$ & 1.96 (1.63 to 2.37$)$ & $2.26(1.85$ to 2.76$)$ \\
\hline
\end{tabular}

\section{Generalisability of the findings}

Comparative mortality analyses show that people in Scotland fare worse than people in England living in similar social positions, suggesting there may be something unusual about Scotland. ${ }^{13}{ }^{14}$ However, a recent study identified 20 regions in the United Kingdom and northern Europe with similar mortality profiles to the west of Scotland, in which Renfrew and Paisley are typical post-industrial towns. ${ }^{15}$ Detailed comparisons revealed that the west of Scotland fared relatively well in terms of current wealth, unemployment, and educational attainment and had all cause mortality slightly above the mean for both men and women older than 65 years. Current smoking rates in the west of Scotland were among the highest in the regions studied, and lung cancer rates among both men and women were the highest. These comparisons suggest the impact of smoking on men and women in all social positions found in Renfrew and Paisley could be expected in similar populations where smoking has been prevalent for many decades.

Impact of smoking on survival and health inequalities Our analyses confirm in a general population the findings of the British male doctors' study that smoking continues to take a heavy toll in later life. ${ }^{1}$ We found that smoking has a sustained impact on the mortality of people in their fifth to 10th decades, regardless of sex, social class, or place of residence. As measured by mortality and survival after 28 years of follow-up, we 
Table $5 \mid$ Age adjusted percentage survival after 28 years follow-up of women and men aged 45-64 years and who never smoked or currently smoked at recruitment categorised by social class

\begin{tabular}{lcc}
$\begin{array}{l}\text { Social class } \\
\text { Women: }\end{array}$ & Never smokers & Current smokers \\
\hline I + II & 65.4 & 40.5 \\
\hline IIIN & 56.5 & 41.6 \\
\hline IIIM & 53.3 & 32.9 \\
\hline IV + V & 55.6 & 35.1 \\
\hline Men: & 52.7 & \\
\hline I+ II & 47.0 & 24.4 \\
\hline IIIN & 38.3 & 23.8 \\
\hline IIIM & 35.7 & 19.3 \\
\hline IV + V & 18.4 \\
\hline IIIN=III non-manual. IIIM=III manual. &
\end{tabular}

found greater health inequality between smokers and never smokers than between people of the same sex and smoking status but different social positions.

Moreover, among both women and men, people in the lowest social positions who had never smoked had substantially better survival rates than smokers in even the highest social classes. After 28 years of follow-up, $56 \%$ of women and $36 \%$ of men who had never smoked in social classes IV and V were still alive, compared with only $41 \%$ of women and $24 \%$ of men who smoked in social classes I and II. To our knowledge, this important finding has not previously been reported.

Our results clearly show that, among people of the same sex and smoking status, there is a survival gradient between the highest and lowest social classes, but it is relatively modest, particularly between smokers, compared with the large differences between never smokers and smokers. Thus, the differences in survival rates between female and male smokers of the highest and lowest social classes were only $5 \%$ and $6 \%$ respectively, whereas the differences between smokers and never smokers of the same sex and social class ranged from $16 \%$ to $28 \%$ (table 5 and fig 2 ).

Consequently, smoking itself was a source of greater health inequality than other factors associated with social position in this population. Further evidence for the population impact of smoking comes from national and international studies using indirect estimates of smoking related mortality. A detailed analysis of mortality in England and Wales concluded that 85\% of the observed inequalities between socioeconomic groups could be attributed to smoking. ${ }^{16}$ The contribution of smoking to socioeconomic inequalities in male mortality was assessed in the US, Canada, England and Wales, and Poland. ${ }^{17}$ The authors concluded that "in these populations, most, but not all, of the substantial social inequalities in adult male mortality during the 1990s were due to the effects of smoking."

Given the small differences in survival between smokers in different social classes, our data suggest that other efforts to improve the socioeconomic circumstances of the least affluent will have little impact on the health of those who continue to smoke. The combination of the greatly increased mortality of smokers with the now much lower prevalence of smoking among the more affluent is the major contributor to the widening health inequalities observed in the UK and other industrialised countries. ${ }^{3}$ Smoking is, of course, not the only cause of health inequalities, as our study shows in the gradients in survival rates among never smokers of different social positions, especially among men.

\section{Sex inequality}

Our study confirms the lower average survival rates of men seen in the UK and elsewhere. ${ }^{1819}$ Although the overall difference can at least be partly explained by higher smoking rates, male smokers, former smokers, and never-smokers consistently fared less well than their female counterparts. Indeed, the differences in survival between women and men of the same social class and smoking status were, with one exception, greater than those between women of different social classes but of the same smoking status. However, women who smoked had lower survival rates than men who had never smoked in all social positions except the lowest. Thus, smoking by women seems to nullify the survival advantage they otherwise have over men.

The differences between men and women who never smoked clearly have other causes. Occupational exposures, alcohol consumption, accidents, and nonaccidental violence are all potentially preventable contributory factors.

Benefits of quitting smoking and tobacco control policy in the UK

Our study provides strong support for the benefits of stopping smoking shown in other studies. ${ }^{1-20}$ Our participants classified as former smokers had on average stopped smoking 12-14 years before they joined the study. During both periods of follow-up, but particularly the second, the mortality of former smokers was closer to that of never smokers than smokers. Recent government policies on tobacco

\section{WHAT IS ALREADY KNOWN ON THIS TOPIC}

Continued tobacco smoking caused greatly reduced survival in later life among British male doctors born before 1930

Higher smoking rates among people in lower social positions are a major contributor to health inequalities related to social position

\section{WHAT THIS STUDY ADDS}

In a Western urban population, never smokers in the lowest social positions had better survival rates than smokers in even the highest social positions

Smoking nullified women's usual survival advantage over men

In this and similar populations, the scope for reducing health inequalities related to social position is probably limited unless many smokers in lower social positions can be enabled to stop smoking 
control and health inequalities in the UK recognise the importance of encouraging and enabling all smokers to quit and of intensifying efforts to reduce smoking rates in disadvantaged areas and groups. ${ }^{21-23}$ Our study thus reinforces the logic of current action in the UK and other countries to encourage smokers to quit. As more than $23 \%$ of UK adults still smoke ${ }^{24}$ rising to over $40 \%$ in some areas, ${ }^{25}$ continued concerted efforts will be required to reduce the burden of smoking related illness and premature death. If this is not done, health inequalities related to social position can only widen.

\section{Conclusion}

This study provides further evidence that cigarettes indiscriminately damage and kill their users, regardless of social position. It shows for the first time that smokers of all social positions have poorer survival than never smokers in low social positions and that smoking by women cancels out their survival advantage over men. In essence, neither affluence nor being female offers a defence against the toxicity of tobacco. Our findings underline the need for global tobacco control and support for all smokers who wish to quit, but with efforts concentrated particularly on areas and groups where smoking rates are highest.

Victor Hawthorne conducted the original Midspan studies, and Pauline MacKinnon is the Midspan administrator.

Contributors: LG had the original idea for the paper and the visual display of the data. CLH conducted the statistical analyses. All the authors participated in designing the analyses, interpreting the results, and writing the manuscript. $L G$ is the guarantor for the study.

Funding: LG and DSG are employees of NHS Health Scotland. CLH and GCMW are employees of the University of Glasgow. The analyses conducted by CLH were funded by NHS Health Scotland. The original Renfrew Paisley study was funded by the King Edward Memorial Fund and the Scottish Home and Health Department.

Independence of authors: The views expressed in this paper are those of the authors alone.

Competing interests: None declared.

Ethical approval: Not required.

1 Doll R, Peto R. Boreham J, Sutherland I. Mortality in relation to smoking: 50 years observations on male British doctors. BMJ 2004;328:1519-33.

2 Commission on Social Inequalities in Health. Achieving health equity: from root causes to fair outcomes. Geneva: World Health Organization, 2007.

3 Jarvis $M$, Wardle J. Social patterning of individual health behaviours: the case of cigarette smoking. In: Marmot M, Wilkinson R, eds. Socia determinants of health. Oxford: Oxford University Press, 1999.

4 Gordon D, Shaw M, Dorling D, Davey Smith G, eds. Inequalities in health. Bristol: Policy Press, 1999.

5 Hawthorne VM, Watt GCM, Hart CL, Hole DJ, Smith GD, Gillis CR. Cardiorespiratory disease in men and women in urban Scotland: baseline characteristics of the Renfrew/Paisley (Midspan) study population. Scot Med J 1995;40:102-7.

6 General Register Office. Classification of occupations 1966. London: HMSO, 1966.

7 Carstairs V, Morris R. Deprivation and health in Scotland. Aberdeen: Aberdeen University Press, 1991.
8 Hole DJ, Watt GCM, Davey Smith G, Hart CL, Gillis CR, Hawthorne VM Impaired lung function and mortality risk in men and women: finding from the Renfrew and Paisley prospective population study. BMJ 1996;313:711-5.

9 Davey Smith G, Hart CL, Watt G, Hole D, Hawthorne VM. Individual social class, area-based deprivation, cardiovascular disease risk factors and mortality: the Renfrew and Paisley study. J Epidemiol Community Health 1998;52:399-405.

10 Marang-van de Mheen PJ, Davey Smith G, Hart CL. The health impact of smoking in manual and non-manual social class men and women: a test of the Blaxter hypothesis. Soc Sci Med 1999;48:1851-6.

11 Marang-van de Mheen PJ, Davey Smith G, Hart CL, Hole DJ, Phillips AN. The influence of gender, social circumstances and smoking on survival: the Renfrew and Paisley study. Public Health 2000;114:117-22.

12 Scottish Government. Scottish household survey annual report 2007 web tables-health and caring (Table 10.4.5). (www.scotland.gov. uk/Topics/Statistics/16002/Tables2007Health).

13 Uren Z, Fitzpatrick J, Reid A, Goldblatt P. Geographic variation in mortality by social class and alternative social classifications. In: Geographic variations in health. London: Stationery Office, 2001. (DS No 16.)

14 Hanlon P, Lawdor R, Buchanan D, Redpath A, Walsh D, Wood R, et al. Why is mortality in Scotland higher than England and Wales? Decreasing influence of socioeconomic deprivation between 1981 and 2001 supports the existence of a "Scottish effect." J Public Health 2005;27:199-204

15 Walsh D, Taulbut M, Hanlon P. The aftershock of deindustrialisation Trends in mortality in Scotland and other parts of post-industrial Europe. Glasgow: Glasgow Centre for Population Health, 2008. (www.gcph.co.uk/component/option,com_docman/task,cat_view/ gid, 52/Itemid,71/)

16 Law M, Morris J. Why is mortality higher in poorer areas and in more northern areas in England and Wales? J Epidemiol Community Health 1998; 52:344-52.

17 Jha P, Peto R, Zatonski W, Boreham J, Jarvis M, Lopez A. Social inequalities in male mortality from smoking: indirect estimation from national death rates in England and Wales, Poland and North America. Lancet 2006;368:367-70.

18 General Register Office for Scotland. Scotland's population in 2006. The Registrar General's annual review of demographic trends. Edinburgh: National Statistics, 2007. (www.gro-scotland.gov.uk/files1/stats/scotlands population-2007-the-register-generals-annual-review-153rdedition/j994410.htm)

19 Review of the Registrar General on deaths in England and Wales 2004. London: National Statistics, 2006. (www.statistics.gov.uk/ downloads/theme_health/Dh1_37_2004/DH1_no_37.pdf)

20 Peto R, Darby S, Deo H, Silcocks P, Whitley E, Doll R. Smoking, smoking cessation, and lung cancer in the UK since 1950: combination of national statistics with two case control studies. BMJ 2000;321:323-9.

21 Scottish Executive. A breath of fresh air for Scotland. Tobacco contro action plan. Edinburgh: Scottish Executive, 2004. (www.scotland. gov.uk/Publications/2004/01/18736/31540)

22 Scottish Government. Equally well: report of the ministerial working group on health inequalities. Edinburgh: Scottish Government, 2008. (www.scotland.gov.uk/Publications/2008/06/25104032/2)

23 Department of Health. Health inequalities: progress and next steps. London: DH, 2008. (www.dh.gov.uk/en/Publicationsandstatistics/ Publications/PublicationsPolicyAndGuidance/DH_085307)

24 Office for National Statistics. Smoking and drinking among adults 2006. London: ONS, 2008. (www.statistics.gov.uk/downloads/ theme_compendia/GHS06/ Smokinganddrinkingamongadults2006.pdf)

25 Taulbut M, Gordon D, McKenzie K. Tobacco smoking in Scotland. An epidemiological briefing. Edinburgh: Scottish Public Health Observatory, 2008. (www.scotpho.org.uk/home/Publications/ scotphoreports/pub_tobaccobriefing.asp)

Accepted: 16 December 2008 